\title{
Influences of Hyperbranched Polyester Modification on the Crystallization Kinetics of Isotactic Polypropylene/Graphene Oxide Composites
}

\author{
Zengheng Hao ${ }^{1}, \mathrm{Lu} \mathrm{Li}^{1,2, *}$, Bo Yang ${ }^{1,3, *}$, Xingyue Sheng ${ }^{1}$, Xia Liao ${ }^{2}$, Leilei He ${ }^{1}$ and Pan Liu ${ }^{1}$ \\ 1 Chongqing Zhixiang Paving Technology Engineering Co., Ltd., Chongqing 401336, China; \\ haozengheng@cmhk.com (Z.H.); shengxingyue@cmhk.com (X.S.); heleilei@cmhk.com (L.H.); \\ liupan@cmhk.com (P.L.) \\ 2 College of Polymer Science and Engineering, State Key Laboratory of Polymer Materials Engineering, \\ Sichuan University, Chengdu 610065, China; liaoxia@scu.edu.cn \\ 3 School of Civil Engineering, Chongqing Jiaotong University, Chongqing 400074, China \\ * Correspondence: lilu_sky@foxmail.com (L.L.); yangbo@cmhk.com (B.Y.)
}

Received: 25 December 2018; Accepted: 27 February 2019; Published: 6 March 2019

\begin{abstract}
In this study, the hyperbranched polyester grafted graphene oxide (GO-H202) was synthesized, and the isotactic polypropylene/graphene oxide (iPP/GO) composites were prepared. Results of X-ray photoelectron spectra (XPS), Fourier transform infrared (FT-IR), and transmission electron microscopy (TEM) revealed the successful synthesis of GO-H202, while thermogravimetric analysis (TGA) indicated that the weight ratio of grafting was about $35 \mathrm{wt} \%$. Differential scanning calorimetry (DSC) and polarized optical microscopy (POM) were carried out to investigate the role of GO and GO-H202 on the crystallization kinetics of the composites. Results suggested that the addition of GO enhanced the nucleation rate and crystallizability of the composites, while GO-H202 exhibited a higher crystallization acceleration effect compared to neat GO; results of isothermal crystallization kinetics and self-nucleation isothermal crystallization kinetics showed that both the overall crystallization rate and crystal growth rate increase after the addition of GO and GO-H202, and the crystallization acceleration of GO-H202 became evidently stronger compared to GO. Moreover, the variation trends of Avrami exponent $n$ with the isothermal crystallization temperature $T_{\text {CISO }}$ changed significantly after the addition of GO or GO-H202, which might imply that the addition of GO and GO-H202 lead to different crystallization dimensionalities during the isothermal crystallization of the composites. The related mechanism was also discussed.
\end{abstract}

Keywords: isotactic polypropylene; graphene oxide; hyperbranched polyester; crystallization kinetics; nucleation and crystal growth

\section{Introduction}

Isotactic polypropylene (iPP) is one of the most widely used general-purpose plastics nowadays because of its low price and outstanding properties, such as its mechanical properties, chemical stability, nontoxicity, and easy processing [1-6]. iPP also exhibits interesting polymorphic behavior, which has many crystalline structures, including $\alpha$ - [2,7-9], $\beta$ - [10-13], and $\gamma$-phase [14,15]. Among these crystal forms, the $\alpha$-phase is the most stable and commonly seen crystalline form and can be obtained under practical processing conditions. $\beta$-Phase is a thermodynamically metastable crystalline form which can only be obtained under certain ways [16-19], such as crystallization in the melt shear field [18], in a temperature gradient field [20], or in the presence of $\beta$-nucleating agents [13,21,22]. To meet the increasing performance requirements of the products and to further increase the mechanical properties are some of the main challenges in the related area. 
Introduction of inorganic fillers has been found to be an efficient way to improve the strength of iPP without sacrificing other properties. Graphene is a two-dimensional atomic crystal composed of a single atomic layer of carbon atoms connected by $s p^{2}$ hybridization, which has a thickness of only $0.34 \mathrm{~nm}$, known as the thinnest material [23]. This special structure provides graphene excellent properties such as outstanding electrical conductivity, thermal conductivity, high elastic modulus, larger specific surface area, and fractional quantum hall effect [24-26]. However, the strong Van der Waal force of graphene results in the characteristics of hydrophobicity and easy agglomeration, and the application of graphene is greatly limited [27]. Graphene oxide (GO) is a precursor of graphene, which has similar structure to graphene and can be used as the preferred choice for reinforcing polymers because of its carboxyl groups and carbonyl groups at the edge and hydroxyl groups and epoxides groups on the matrix $[28,29]$. The existence of these functional groups improves the hydrophilicity of GO, which can also react with polar polymers. For nonpolar polymers, functional groups are introduced to modify the surface of GO. Surface-functionalized GO exhibits good interfacial compatibility in nonpolar polymers such as iPP and polystyrene [13,30]. Composite modification of iPP with GO is an important way to make high-performance iPP materials.

Hyperbranched polymers have a lower branching efficiency than dendrimers while enjoying many useful properties [31-34]. The highly branched architecture minimizes chain-chain ability and low melt viscosity of these polymers [35], which is compatible with iPP. The presence of numerous functional groups $(-\mathrm{OH})$ provides high reaction activity with inorganic filler, providing it the possibility to be desirable macromolecular surface modifier for GO to further enhance the compatibility and dispersion in iPP.

In this study, the GO grafted with hyperbranched polyester was prepared to enhance the interaction between GO and iPP matrix. Then, PP/GO composites were prepared to study the impacts of raw GO and hyperbranched polymer ester grafted GO on the detailed isothermal crystallization kinetics of the composites, which is an important issue that has not been reported before.

\section{Experimental Section}

\subsection{Materials}

iPP with a trade name of T38F, molecular weight of 347,200 and dispersion index of 3.63, average isotacticity of $97 \%$, and melt index of $3.0 \mathrm{~g} / 10 \mathrm{~min}\left(2.16 \mathrm{~kg}, 230^{\circ} \mathrm{C}\right)$ was purchased from Lanzhou Petroleum Chemical Co., Ltd. (Lanzhou, China); Graphene oxide (GO) was purchased from Henan Angstron Graphene Technology Co., Ltd. (Zhengzhou, China); Hyperbranched polyester H202 (Scheme 1, $M_{w}=1200 \mathrm{~g} / \mathrm{mol}$, hydroxyl number = $520 \mathrm{mg} \mathrm{KOH} / \mathrm{g}$ polymer, denoted as Hyper H202 in this study) was purchased from Shanghai Seebio Biotech, Inc., (Shanghai, China) and used as received; $\mathrm{N}, \mathrm{N}$-dimethylformamide (DMF) was purchased from Sinopharm Chemical Reagent Beijing Co., Ltd. (Beijing, China), China, and was used as received.

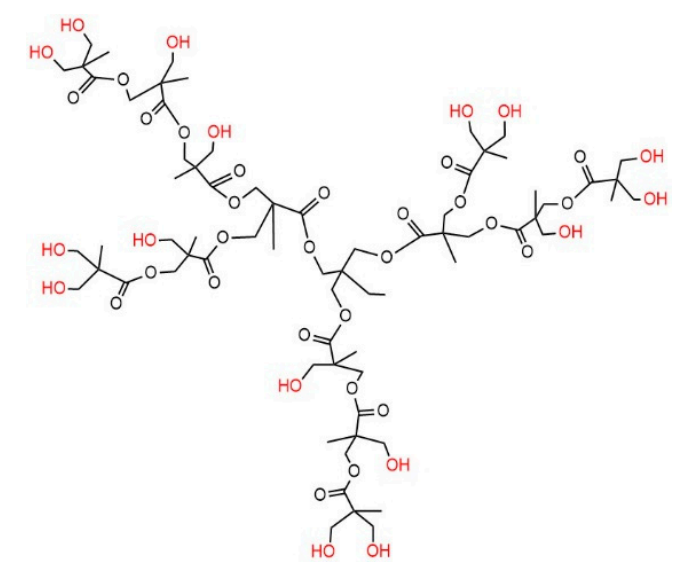

Scheme 1. Chemical structure of the hyperbranched polyester H202. 


\subsection{Grafting of the Graphene Oxide}

Reaction principle of hyperbranched polyester H202 modified graphene oxide is shown in Scheme 2. The hyperbranched polyester $\mathrm{H} 202$ and GO were dissolved in DMF at room temperature and then irradiated using ultrasound for $1 \mathrm{~h}[21,36]$. Then, they were heated up to $120^{\circ} \mathrm{C}$ and reacted under magnetic stirring for $24 \mathrm{~h}$. After that, they were cooled to room temperature slowly and filtered using PVDF filtration membrane with an average pore diameter of $0.22 \mu \mathrm{m}$. The product was firstly washed by acetone and filtered several times to eliminate the unreacted H202 and extra solvent. Each time, the washed acetone was taken for FT-IR analysis, and the washing was finished until the washed acetone had the same FT-IR spectra compared with pure acetone. The collected material was then heated under vacuum drier at $80^{\circ} \mathrm{C}$ for $24 \mathrm{~h}$, and the final product, GO grafted with $\mathrm{H} 202$ (named as GO-H202), was obtained. The obtained raw GO and H202-grafted GO powder was vacuum dried at $60{ }^{\circ} \mathrm{C}$ for $24 \mathrm{~h}$ before use.

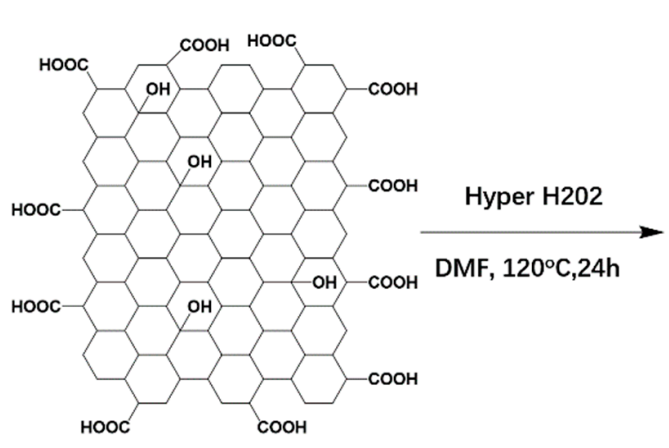

GO

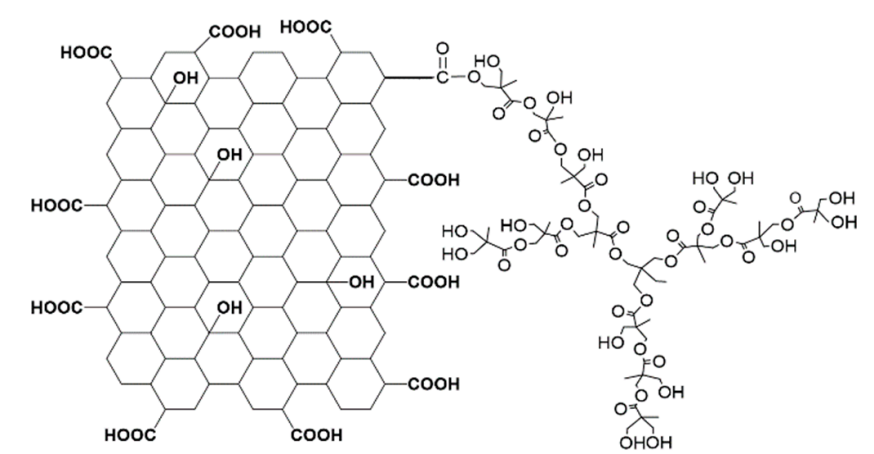

GO-H202

Scheme 2. Reaction principle of hyperbranched polyester H202 modified graphene oxide (GO).

\subsection{Preparation of $i P P / G O$ Composites}

The dried GO or GO-H202 powder was ultrasonically dispersed in a $200 \mathrm{~mL}$ xylene solution for $30 \mathrm{~min}$. Then, a certain amount of iPP was added to the solution, keeping the mass fraction of GO or GO-H202 at $5 \%$. After that, the solution was stirred at $130{ }^{\circ} \mathrm{C}$ for $2 \mathrm{~h}$. Finally, the mixture was vacuum filtered and dried for $24 \mathrm{~h}$ to obtain iPP/GO and iPP/GO-H202 master batch. The iPP/GO master batch and neat iPP were mixed using twin-extruder to obtain the iPP/GO and iPP/GO-H202 composites, in which the concentration of GO or GO-H202 was $1 \mathrm{wt} \%$. Then, a pressure-molding machine was used to press the samples. The neat iPP, iPP/GO, and iPP/GO-H202 were named as PP, GPP, and GHPP in this manuscript.

\subsection{Characterization}

\subsubsection{X-ray Photoelectron Spectra (XPS)}

XPS was carried out by the use of an ESCALAB 250 photoelectron spectrometer (ThermoFisher Scientific, Waltham, MA, USA) with Al K $\alpha(1486.6 \mathrm{eV})$ as the X-ray source set at $150 \mathrm{~W}$ and a pass energy of $30 \mathrm{eV}$ for a high-resolution scan.

\subsubsection{Fourier Transform Infrared (FT-IR)}

A Nicolet iS50 FT-IR spectrometer (Thermo Scientific, Waltham, MA, USA) was used to determine the FT-IR spectra of the samples. The FT-IR was recorded at a resolution of $4 \mathrm{~cm}^{-1}$, and 20 scans were averaged for each spectrum. The scanning range was $4000-400 \mathrm{~cm}^{-1}[37,38]$. 


\subsubsection{Thermogravimetric Analysis (TGA)}

TGA was carried out on a TA Q5000IR thermo-analyzer instrument (TA Instruments Inc., New Castle, DE, USA) from room temperature to $800{ }^{\circ} \mathrm{C}$ at a linear heating rate of $10{ }^{\circ} \mathrm{C} / \mathrm{min}$ under $\mathrm{N}_{2}$ and air atmosphere (flow rate of $100 \mathrm{~mL} / \mathrm{min}$ ).

\subsubsection{Transmission Electron Microscopy (TEM)}

To study the morphologies of the GO and GO-H202, transmission electron microscopy (TEM, Tecnai G2 F20, FEI, Hillsboro, OR, USA) was applied [39].

\subsubsection{Differential Scanning Calorimetry (DSC)}

All the calorimetric experiments were carried out using a Mettler Toledo DSC3+ differential scanning calorimetry (DSC) under nitrogen atmosphere $(50 \mathrm{~mL} / \mathrm{min})$. Calibration for the temperature scale was performed using indium as a standard to ensure reliability of the data obtained $[40,41]$. In order to ensure the homogeneity of samples and good contact between sample and pan, the virgin polymer was molded at $190{ }^{\circ} \mathrm{C}, 10 \mathrm{MPa}$ for 5 mins into sheets of uniform thickness about $500 \mu \mathrm{m}$. Then, $3 \mathrm{mg}$ round samples were punched out of the sheets.

The degree of crystallinity, $X_{\mathrm{c}}$, was calculated from the ratio $\triangle H_{\mathrm{m}} /\left(\triangle H_{\mathrm{u}} \cdot W_{f}\right) . \Delta H_{\mathrm{m}}$ and $\triangle H_{\mathrm{u}}$ were the apparent and completely crystalline heats of fusion, respectively, and $W_{f}$ was the weight percentage of the polymer in the composites. $\triangle H_{\mathrm{m}}$ was determined by linear interpolation of the baseline between the clear-cut end of the melting endotherm and its onset arbitrarily taken at $90{ }^{\circ} \mathrm{C}$ for all samples, and $\triangle H_{\mathrm{u}}$ was $209 \mathrm{~J} / \mathrm{g}$ for iPP [42-44].

\subsubsection{Isothermal Crystallization Kinetics}

The isothermal crystallization studies were performed according to the following procedures [45-47]:

(a) Samples were heated from 50 to $200^{\circ} \mathrm{C}$ at $10^{\circ} \mathrm{C} / \mathrm{min}$ and kept for $5 \mathrm{~min}$ to erase any previous thermal history.

(b) Samples were cooled down to the desired crystallization temperature $T_{\text {cISO }}$ at $50{ }^{\circ} \mathrm{C} / \mathrm{min}$.

(c) Samples were isothermally kept for a certain time to complete crystallization.

\subsubsection{Self-Nucleation Isothermal Crystallization Kinetics}

The self-nucleation isothermal crystallization kinetics was measured according to the manner proposed by Muller et al. [48,49]:

(a) The self-nucleating behavior of samples was firstly measured according to Fillon et al. [50-52], and the temperature region for the self-nucleation domain (Domain II) was obtained.

(b) The samples were heated from 50 to $200{ }^{\circ} \mathrm{C}$ at $10{ }^{\circ} \mathrm{C} / \mathrm{min}$ and held for $5 \mathrm{~min}$ to destroy any residual nuclei.

(c) After that, samples were cooled to $50{ }^{\circ} \mathrm{C}$ at $10{ }^{\circ} \mathrm{C} / \mathrm{min}$ and held for $2 \mathrm{~min}$ to create a "standard" thermal history [53], and then they were heated to the self-nucleating temperature (denoted as $T_{S N}$, the lowest temperature within Domain II is preferred) and kept for $5 \mathrm{~min}$.

(d) Then, it was rapidly cooled to the predetermined crystallization temperature $\left(T_{c S N}\right)$ and held for a certain time to allow the completion of crystallization.

(e) Finally, the sample was heated to $200^{\circ} \mathrm{C}$ at a rate of $10^{\circ} \mathrm{C} / \mathrm{min}$.

\subsubsection{Polarized Optical Microscopy (POM)}

The morphology of the samples was studied with a ZEISS MC-80 polarized light microscope (Carl Zeiss AG., Jena, Germany) equipped with a LINKAMTP-91 hot stage and a camera system. Thin melt-samples were prepared between microscope coverslips. Under a nitrogen atmosphere, they 
were melted at $200{ }^{\circ} \mathrm{C}$ for $5 \mathrm{~min}$ to erase the thermal history of the sample, and then they were rapidly cooled down to $130^{\circ} \mathrm{C}$ for isothermal crystallization.

\section{Results and Discussions}

\subsection{Chemical Structure of GO-H2O2}

To investigate the chemical structure and constitution of H202, GO and GO-H202, the measurements of XPS, FT-IR, and TGA were performed, as shown in Figure 1. From Figure 1a, the XPS spectra and the fractions of $\mathrm{O}$ and $\mathrm{C}$ of the samples were calculated, as shown in Table 1.
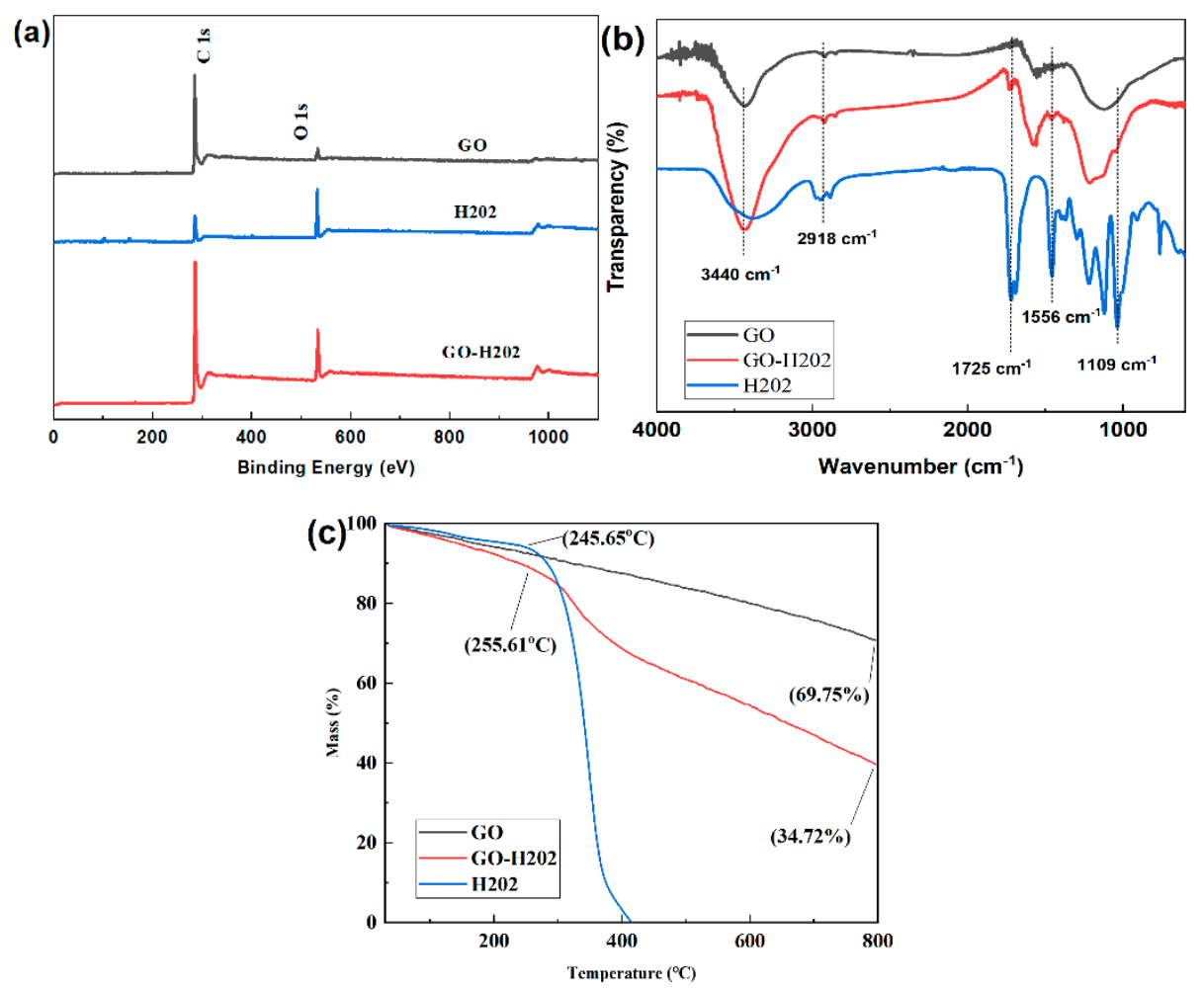

Figure 1. XPS (a), FT-IR spectrum (b) and TGA curves (c) of hyperbranched polyester H202, graphene oxide (GO), and GO-H202.

Table 1. Fractions of $\mathrm{C}$ and $\mathrm{O}$ of $\mathrm{H} 2 \mathrm{O2}, \mathrm{GO}$, and GO-H202.

\begin{tabular}{cccc}
\hline Samples & O 1s (\%) & C 1s (\%) & $n(\mathbf{O}) / \boldsymbol{n}(\mathbf{C})$ \\
\hline H202 & 60.5 & 39.5 & 1.53 \\
GO & 16.2 & 83.8 & 0.19 \\
GO-H202 & 27.7 & 72.3 & 0.38 \\
\hline
\end{tabular}

Figure 1a and Table 1 reveal that after grafting H202, the O content of GO-H202 (27.7\%) is obviously higher than that of GO $(16.2 \%)$. The $\mathrm{O} / \mathrm{C}$ ratio, $n(\mathrm{O}) / n(\mathrm{C})$, of GO-H202 is twice compared to $\mathrm{GO}$, indicating that $\mathrm{H} 202$ has been successfully grafted onto GO.

On the other hand, Figure 1b showing the FT-IR reveals that for hyperbranched polyester H202, the wide peak at $3400 \mathrm{~cm}^{-1}$ represents the vibration of $-\mathrm{OH}$ group, while signals at the wavenumbers of $2918 \mathrm{~cm}^{-1}$ and $2888 \mathrm{~cm}^{-1}$ represent the asymmetric and symmetric vibrations of $-\mathrm{CH}_{3}$ and $-\mathrm{CH}_{2}$, respectively. The peak at the wavenumber of $1734 \mathrm{~cm}^{-1}$ is the stretching vibration peak of carbonyl from the polyester [35]. From the FT-IR spectrum of GO-H202, the extra peak at the wavenumber of $1734 \mathrm{~cm}^{-1}$ can be seen compared with that of neat GO, suggesting that $\mathrm{H} 202$ has been successfully grafted onto GO. 
The TGA curves of H202, GO, and GO-H202 in Figure 1c show that the degradation of $\mathrm{H} 202$ initiates at about $245^{\circ} \mathrm{C}$ and finishes at about $410{ }^{\circ} \mathrm{C}$. Interestingly, a significant weight loss of GO-H202 is observed at the same temperature range, which cannot be observed from the TGA curve of neat GO, suggesting that the grafting of $\mathrm{H} 202$ onto GO is successful. Moreover, the grafting weight ratio of $\mathrm{H} 202$ is about $35 \mathrm{wt} \%$ of GO.

To directly observe the morphology of the fillers, TEM was performed, as shown in Figure 2. Clearly, compared with neat GO, many dark dots can be observed from the TEM image of GO-H202, which might be evidence for the successful grafting of H202 onto GO.
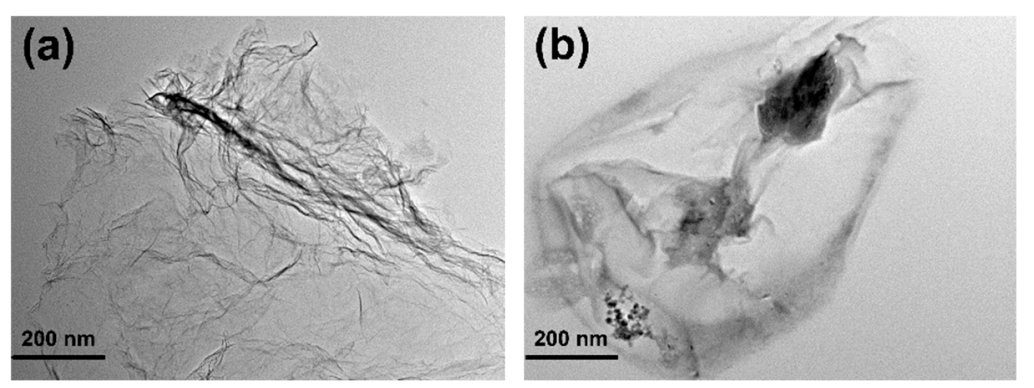

Figure 2. TEM images of (a) GO and (b) GO-H202.

\subsection{DSC Cooling and Heating Behavior of the Composites}

The DSC cooling and subsequent melting curves at the cooling and heating rates of $10{ }^{\circ} \mathrm{C} / \mathrm{min}$ are shown in Figure 3, and the corresponding onset, endset and peak temperatures of crystallization ( $T_{\text {conset }}, T_{\text {cendset }}$ and $\left.T_{c}\right)$; the peak, onset, and endset temperatures of melting $\left(T_{m}, T_{\text {monset }}\right.$ and $\left.T_{\text {mendset }}\right)$; and the relative degree of crystallinity $X_{\mathrm{c}}$ are shown in Table 2.
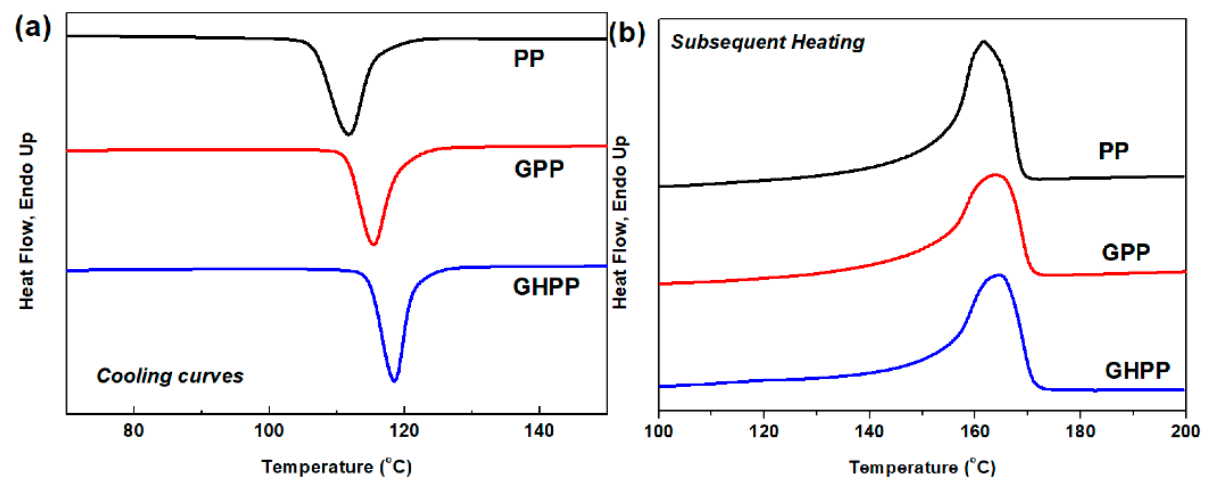

Figure 3. (a) Differential scanning calorimetry (DSC) cooling curves and (b) subsequent heating curves of the samples. The cooling and subsequent heating rates were $10^{\circ} \mathrm{C} / \mathrm{min}$.

Table 2. Crystallization and melting parameters of polypropylene (PP), iPP/GO (GPP), and iPP/GO-H202 (GHPP).

\begin{tabular}{ccccccccc}
\hline & \multicolumn{4}{c}{ Cooling Scan } & \multicolumn{4}{c}{ Subsequent Heating Scan } \\
\cline { 2 - 9 } Sample & $\boldsymbol{T}_{\boldsymbol{c}}$ & $\boldsymbol{T}_{\text {conset }}$ & $\boldsymbol{T}_{\text {cendset }}$ & $\begin{array}{c}\text { Width } \\
\left({ }^{\circ} \mathbf{C} \mathbf{C}\right)\end{array}$ & $\begin{array}{c}\boldsymbol{T}_{\boldsymbol{m}} \\
\left({ }^{\circ} \mathbf{C}\right)\end{array}$ & $\begin{array}{c}\left.\boldsymbol{T}_{\text {monset }} \mathbf{C}\right) \\
\left({ }^{\circ} \mathbf{C}\right)\end{array}$ & $\begin{array}{c}\boldsymbol{T}_{\text {mendset }} \\
\left({ }^{\circ} \mathbf{C}\right)\end{array}$ & $\begin{array}{c}\boldsymbol{X}_{\boldsymbol{c}} \\
(\%)\end{array}$ \\
\hline PP & 111.7 & 118.5 & 106.5 & 12.0 & 161.5 & 153.1 & 166.0 & 48.6 \\
GPP & 115.4 & 121.0 & 110.7 & 10.3 & 163.6 & 153.9 & 167.2 & 49.5 \\
GHPP & 118.5 & 122.6 & 114.4 & 8.2 & 164.8 & 155.2 & 168.7 & 50.9 \\
\hline
\end{tabular}

As can be seen from Figure 3 and Table 2, compared with PP, the $T_{\mathcal{c}}, T_{\text {conset, }}$, and $T_{\text {cendset }}$ on the crystallization curve; the $T_{m}, T_{\text {monset }}$, and $T_{\text {mendset }}$ on the melting curve; and the relative degree of crystallinity $X_{c}$ of GPP increase evidently, indicating an enhancement of nucleation rate and 
crystallizability of the composites after the addition of GO. Moreover, the lamellar thickness is enhanced as well. Interestingly, after the addition of GO-H202 (GHPP), these parameters further increase compared with GO, revealing the higher crystallization acceleration effect of GO-H202.

\subsection{Isothermal Crystallization Kinetics of the Composites}

To further investigate the influence of GO and GO-H202 on the crystallization kinetics of the composites, the isothermal crystallization of the composites was investigated in this section. The isothermal crystallization curves and the relative degrees of crystallinity $\left(X_{t}\right)$ at the isothermal crystallization temperatures $\left(T_{\text {cISO }}\right)$ of $120-124^{\circ} \mathrm{C}$ are shown in Figure 4 as a function of crystallization time. The corresponding exothermic DSC curves are also presented in Figure 4 . The $X_{t}$ is a relative value and could be defined as follows [54-56]:

$$
X_{t}=\int_{0}^{t}(d H / d t) d t / \int_{0}^{\infty}(d H / d t) d t
$$

where $\mathrm{d} H_{\mathrm{c}}$ denotes the measured enthalpy of crystallization during isothermal time interval $\mathrm{d} t$. The limits $t$ and $\infty$ denote the elapsed time during the crystallization and at the end of the crystallization process, respectively.
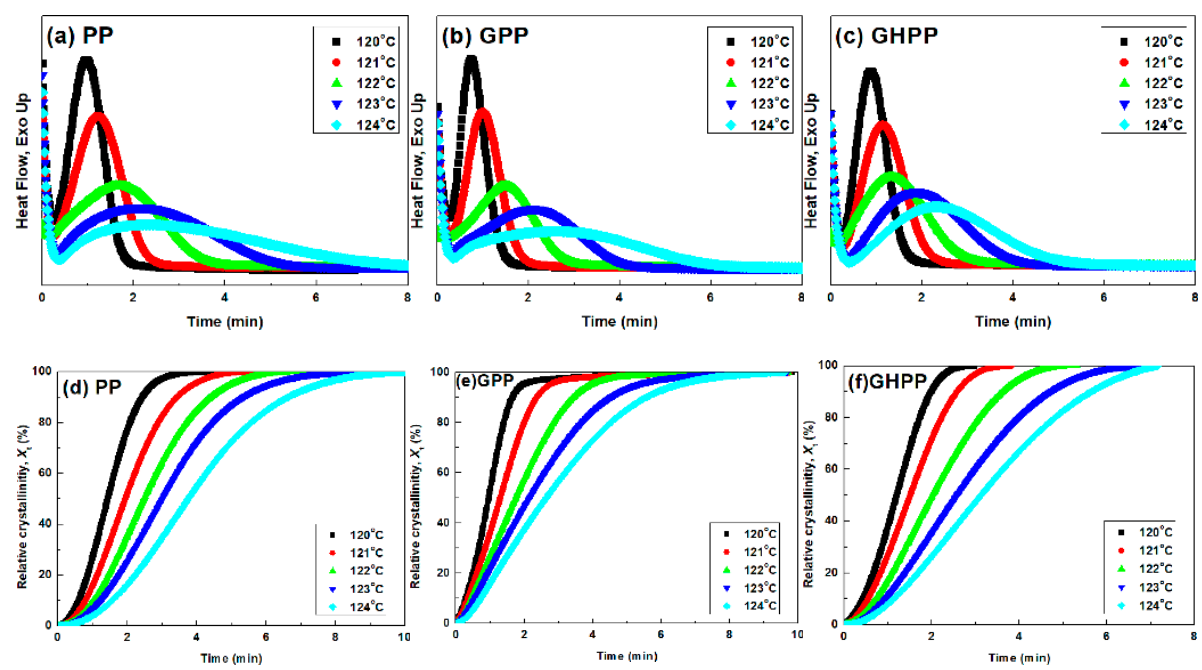

Figure 4. DSC isothermal crystallization curves and plots of relative crystallinity versus crystallization time for PP, GPP and GHPP at $T_{\text {cISO }}=120-124^{\circ} \mathrm{C}$.

Figure 4 reveals that for all the samples, obvious dependence of the isothermal crystallization rate on crystallization temperature $T_{\text {cISO }}$ can be observed. As the supercooling (the difference between the melting and crystallization temperature) decreases, the exothermal peak becomes broader, indicating a decrease of crystallization rate as the $T_{\text {cISO }}$ increases.

The half crystallization time of overall crystallization $\left(t_{00.5}\right)$ is a direct measure of overall crystallization rate, which can be defined as the half period crystallization. The reciprocal of $t_{00.5}$, represented by $G_{00.5}$ (Equation (2)) can be used as a parameter characterizing the crystallization rate of the sample.

$$
G_{00.5}=1 / t_{o 0.5}
$$

Moreover, the Avrami model was employed to analyze the isothermal crystallization kinetics of the samples. The logarithmic form of Avrami model is expressed as Equation (3):

$$
\operatorname{In}\left[-\operatorname{In}\left(1-X_{t}\right)\right]=\operatorname{In} k_{n}+n \operatorname{Int}
$$


where $X_{t}$ is relative degree of crystallinity at crystallization time $t, n$ is the Avrami exponent, and $k_{n}$ represents the crystallization rate parameter involving both the nucleation and growth rate of crystals. By fitting the experimental data to Equation (3), the values of $n$ and $k_{n}$ can be obtained from the slope and intercept of the plots of $\log \left[-\ln \left(1-X_{t}\right)\right]$ versus $\log t$ for each cooling rate shown in Figure 5.
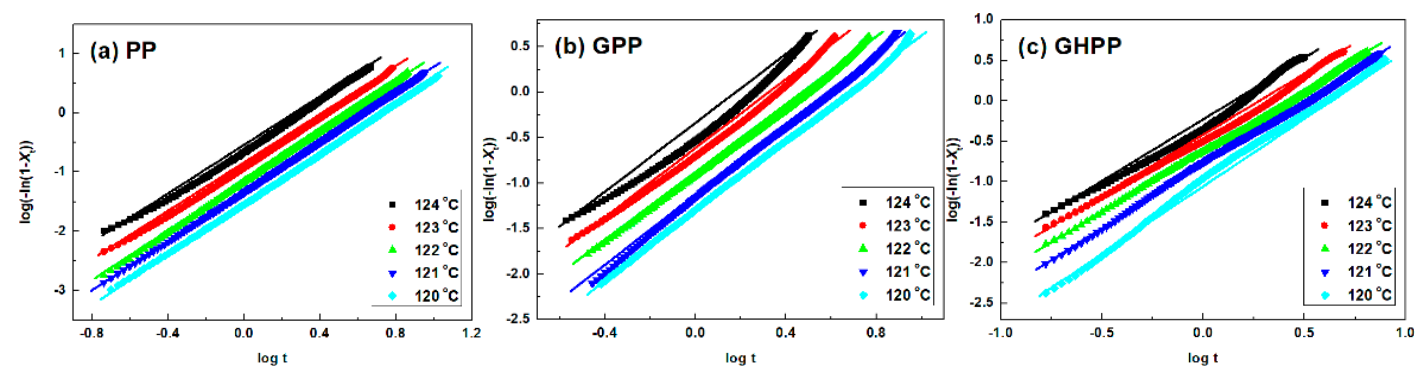

Figure 5. Avrami plots of $\log \left[-\ln \left(1-X_{t}\right)\right]$ versus $\log$ t for isothermal crystallization process for (a) neat PP (b) GPP, and (c) GHPP.

The $t_{00.5}, G_{00.5}, n$, and $k_{n}$ were calculated and plotted in Figure 6 as a function of crystallization temperature $\left(T_{\text {cISO }}\right)$.
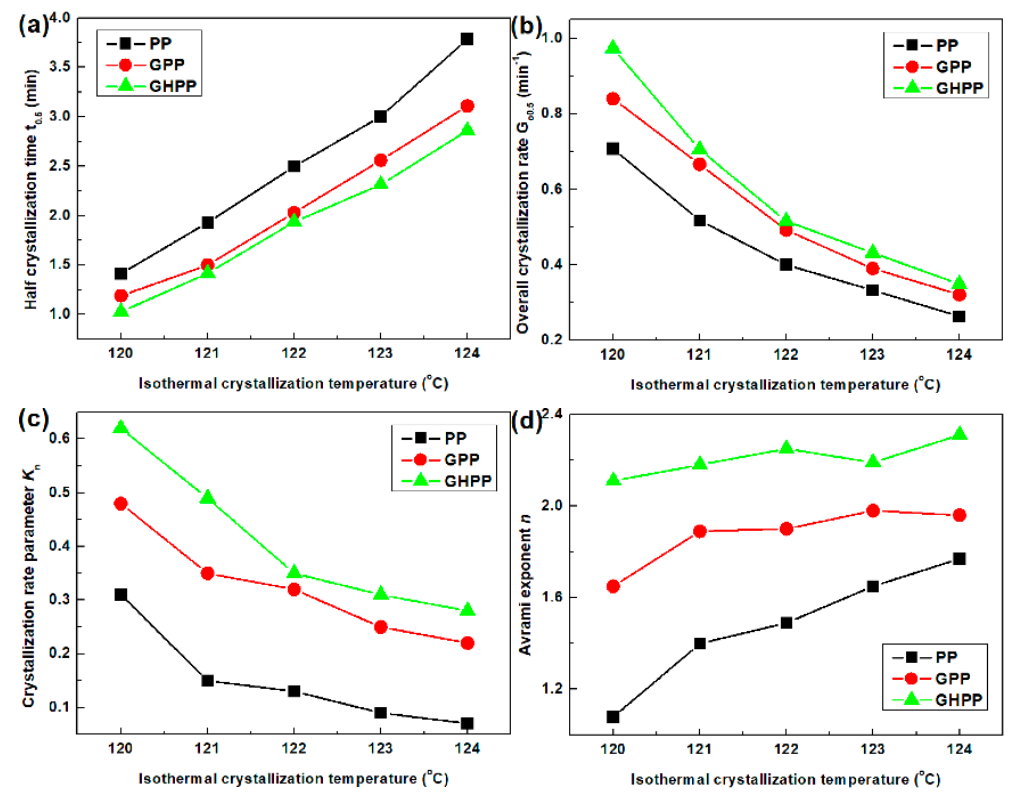

Figure 6. (a) Half crystallization time for overall crystallization, $t_{00.5}$, (b) overall crystallization rate parameter, $G_{00.5}$, (c) crystallization rate parameter involving both nucleation and crystal growth, $k_{n}$, and (d) Avrami exponent $n$ of samples as a function of isothermal crystallization temperature.

It can be seen from Figure 6 that for all samples, $G_{00.5}$ decreases gradually with an increase in the crystallization temperature $T_{c I S O}$. At a given $T_{c I S O}$, the $t_{00.5}$ decreases gradually from PP, GPP to GHPP; meanwhile, both the $G_{00.5}$ value and the kinetic parameter $k_{n}$ increase, indicating that the overall crystallization rate (involving both nucleation and crystal growth) increases after the addition of GO and GO-H202. After grafting hyperbranched polyester H202, the crystallization acceleration of GO-H202 becomes stronger compared with GO.

Moreover, the Avrami exponent $n$ is broadly used to describe dimensionality. The regions from lower than 2, 2 to 3, and 3 to 4 correspond to one-, two-, and three-dimensional growth, respectively. As the crystallization temperature increases, the variations of Avrami exponent $n$ of the three samples are quite different from each other. For neat PP, the Avrami exponent $n$ strongly depends on the isothermal crystallization temperature $T_{\text {cISO }}$, while less dependency can be observed for GPP. The $n$ of 
neat PP and GPP are lower than two, corresponding to one-dimensional growth; for GHPP, $n$ exhibits little dependency on the $T_{\text {cISO, }}$ which is higher than two, indicating that the addition of GO-H202 leads to two-dimensional growth during crystallization. Results above imply that the addition of GO and GO-H202 leads to different crystallization dimensionalities during the isothermal crystallization of PP.

\subsection{Self-Nucleation Isothermal Crystallization Kinetics}

In the isothermal crystallization study above, both primary nucleation and crystal growth contribute to the overall crystallization kinetics of PP. Unfortunately, the information about the single nucleation kinetics or the crystal growth kinetics can hardly be obtained. In order to separate the contributions of these two factors, the self-nucleation isothermal crystallization kinetics was carried out. It is assumed that the sample is fully nucleated during the self-nucleation process before the subsequent isothermal crystallization [49,57-59]. After that, the sample is rapidly cooled down and isothermally crystallized at the desired temperature (denoted as $T_{c S N}$ ). In this way, the subsequent isothermal crystallization can be used to study the crystal growth kinetics. In this study, the temperature of self-nucleation treatment was $167^{\circ} \mathrm{C}$ and the value of $T_{c S N}$ was $141-145^{\circ} \mathrm{C}$. The crystallization curves, as well as the curves of the relative degree of crystallinity $\left(X_{t}\right)$ as a function of crystallization time at $T_{c S N}$ are shown in Figure 7.
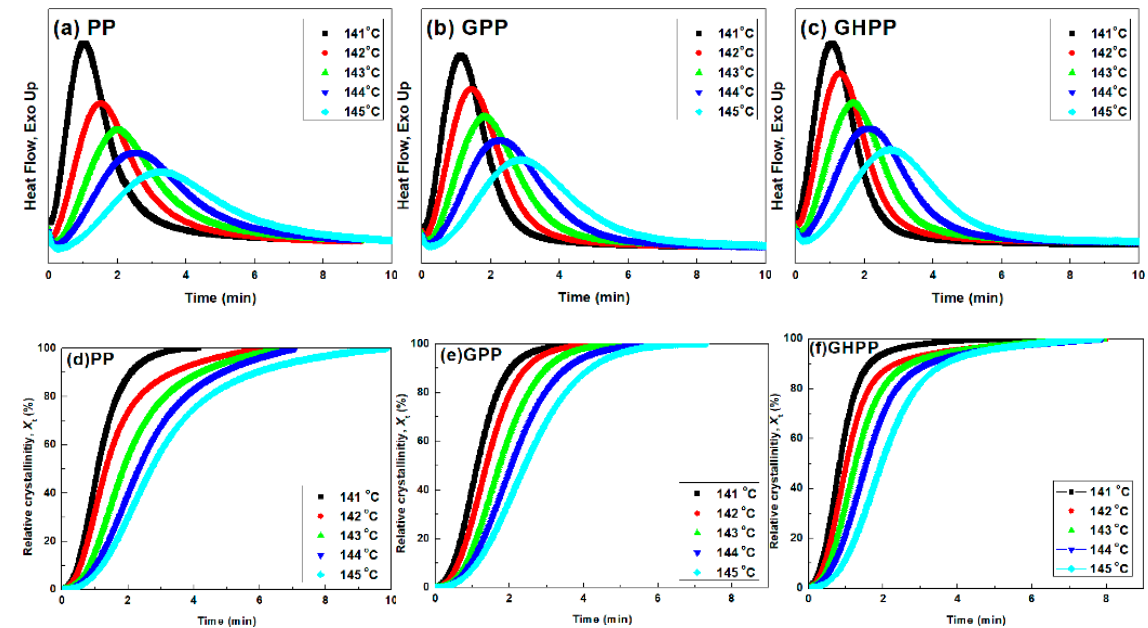

Figure 7. Self-nucleation isothermal crystallization curves (a) neat PP, (b) GPP and (c) GHPP and plots of relative crystallinity vs. crystallization time for (d) neat PP, (e) GPP and (f) GHPP when self-nucleated at $167^{\circ} \mathrm{C}$ for $5 \mathrm{~min}$ and subsequently isothermally crystallized at $T_{C S N}=141-145^{\circ} \mathrm{C}$.

From Figure 7, the half-crystallization time for crystal growth, $t_{c 0.5}$, and the crystal growth rate parameter, $G_{c 0.5}$, were calculated and plotted in Figure 8 as a function of the crystallization temperature $T_{c S N}$.
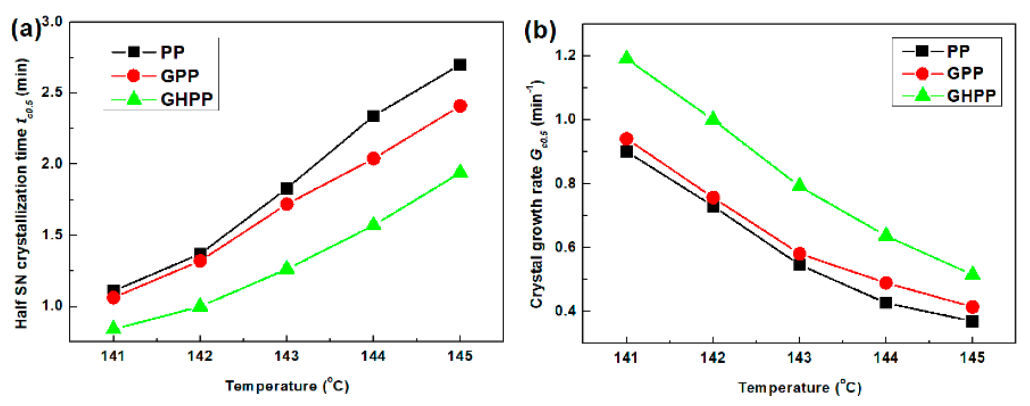

Figure 8. (a) Half crystallization time for crystal growth, $t_{c 0.5}$, and (b) Crystal growth rate parameter, $G_{c 0.5}$, as a function of crystallization temperature $T_{c S N}$ for PP, GPP and GHPP. 
As can be seen from Figure 8 , at the same $T_{c S N}$, from PP, GPP to GHPP, $t_{c 0.5}$ decreases monotonously while $G_{c 0.5}$ increases gradually, indicating that the crystal growth rate of PP increases gradually after the addition of GO and GO-H202.

To understand fully, Hoffman and coworkers $[60,61]$ proposed an equation based on the Turnbull and Fisher equation which is usually referred to as Lauritzen-Hoffman theory (Equation (4)):

$$
G=G_{0} \exp \left[\frac{-U^{*}}{R\left(T_{\mathcal{c}}-T_{\infty}\right)}\right] \exp \left[\frac{-K_{g}}{T_{\mathcal{c}}(\Delta T) f}\right]
$$

where $G$ is the crystal growth rate, $G_{0}$ is the constant and includes all the terms that are temperature-insensitive, $U^{*}$ is the transport activation energy, $R$ is the gas constant, and $R=8.314 \mathrm{~J} /(\mathrm{mol} \cdot \mathrm{K}), U^{*}=6276 \mathrm{~J} / \mathrm{mol} . K_{g}$ is the nucleation parameter, $T_{\infty}$ is the temperature below at which motion ceases and is usually taken as $T_{\infty}=T_{g}-30 \mathrm{~K}, T_{c}$ is the crystallization temperature, $\Delta T=T_{m}{ }^{0}-T_{c}$ is the degree of undercooling, $T_{m}{ }^{0}$ is the equilibrium melting temperature, and $f$ is a factor that accounts for the variation in the enthalpy of fusion, $\Delta h_{f}$, with temperature, and is obtained by $f=2 T_{c} /\left(T_{m}{ }^{0}+T_{c}\right)$.

By rearranging Equation (4), Equation (5) is obtained:

$$
\operatorname{In} G=\operatorname{In} G_{0}-\left[\frac{U^{*}}{R\left(T_{c}-T_{\infty}\right)}\right]-\left[\frac{K_{g}}{T_{c} \cdot \Delta T \cdot f}\right]
$$

$K_{g}$ is also expressed as Equation (6)

$$
K_{g}=n_{c} b_{0} \sigma \sigma_{e} T_{m}^{0} / \Delta h_{f} k
$$

where the $n_{c}$ value depends on the crystallization regime according to Lauritzen-Hoffman theory. At Regime I and Regime III, which occur at low and high undercoolings, respectively, $n_{\mathcal{c}}=4$. However, at Regime II, which occurs at medium undercooling, $n_{c}=2 . \sigma$ and $\sigma_{e}$ are the lateral and end surface free energies of the growing crystal, respectively. $b_{0}$ is the molecular thickness, $\triangle h_{f}$ is the enthalpy of fusion, and $k$ is the Boltzmann constant, $k=1.38 \times 10^{-23} \mathrm{~J} / \mathrm{K}$. It has been reported that, for iPP resins, crystallization occurring at $139-154{ }^{\circ} \mathrm{C}$ was carried out in Regime II. In this study, since the self-nucleation isothermal crystallization temperature is $141-145^{\circ} \mathrm{C}, n_{c}$ is taken to be $2[62,63]$.

$\sigma$ can also be estimated as:

$$
\sigma=\alpha \Delta h_{f} \sqrt{a_{0} b_{0}}
$$

where $\alpha$ was empirically obtained to be 0.1 and $a_{0} b_{0}$ represents the cross-sectional area of the polymer chain [60]. $\triangle h_{f}, a_{0}$, and $b_{0}$ of iPP are supposed to be $1.96 \times 10^{8} \mathrm{~J} / \mathrm{m}^{3}, 5.49 \times 10^{-10} \mathrm{~m}$, and $6.26 \times 10^{-10} \mathrm{~m}$, respectively, based on the literature [60]. Therefore, a value of $\sigma=11.5 \mathrm{erg} \mathrm{cm}^{-2}$ is obtained from Equation (7).

From the plot of $\operatorname{In} G+\frac{U^{*}}{R\left(T_{c}-T_{\infty}\right)}$ of against $\frac{1}{T_{c} \cdot \Delta T \cdot f}$ (shown in Figure 9), the value of $K_{g}$ can be directly calculated from the slope. Therefore, the value of $\sigma_{e}$ was simply estimated by Equations (5) and (6). The results of $K_{g}$ and $\sigma_{e}$ for samples are listed in Table 3.

Table 3. The kinetic parameter for crystal growth $\left(K_{g}\right)$ and interfacial free energies of crystal growth $\left(\sigma_{e}\right)$ under self-nucleation isothermal crystallization process.

\begin{tabular}{ccc}
\hline Sample & $\left.\boldsymbol{K}_{\boldsymbol{g}} \times \mathbf{1 0}^{-\mathbf{4}} \mathbf{( K}^{\mathbf{2}}\right)$ & $\sigma_{e}\left(\mathrm{erg} \mathrm{cm}^{-\mathbf{2}}\right)$ \\
\hline PP & 23.4 & 96.6 \\
GPP & 20.2 & 83.1 \\
GHPP & 17.9 & 76.0 \\
\hline
\end{tabular}




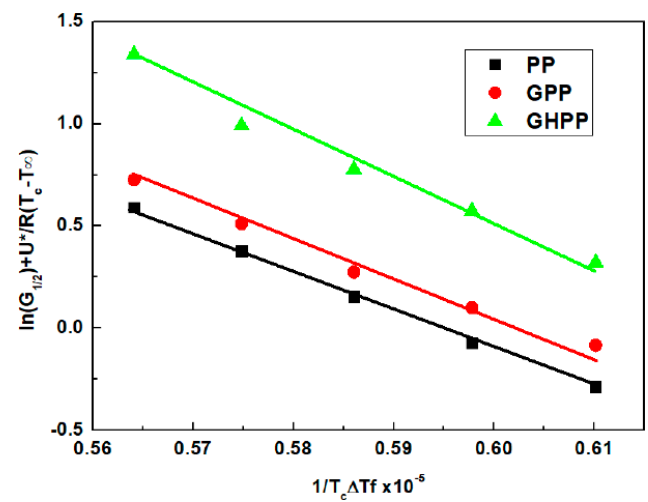

Figure 9. Lauritzen-Hoffman kinetic theory plot for PP, GPP, and GHPP.

The results in Table 3 suggest that, from PP, GPP to GHPP, both the $K_{g}$ and $\sigma_{e}$ decrease gradually, indicating that the surface free energy for crystal growth decreases and the ability for crystal growth increases after the addition of GO and GO-H202. The addition of GO might facilitate the molecular chain regularly arranging into lamellae to a larger degree and therefore increases the growth rate of the crystal. Moreover, the addition of GO-H202 further increases the crystal growth rate of PP benefit from the grafting of $\mathrm{H} 202$ on GO, which might make the GO's dispersion more uniform and act as a foreign nucleating agent for iPP.

In summary, the crystallization kinetics analysis of this manuscript demonstrates that the presence of GO not only enhances the nucleation rate and overall crystallization rate, but also encourages the crystal growth of the PP matrix, possibly due to the external nucleating agent effect of GO; moreover, the grafting of hyperbranched polyester onto GO provides a better compatibility (i.e., better dispersion) with iPP matrix and possibly new nucleation sites for iPP, resulting in the further enhancement of both nucleation rate, crystal growth rate, and overall crystallization rate.

\subsection{Polarized Optical Microscopy Observation}

The overall crystallization kinetics and crystal growth kinetics of the composites were obtained using DSC method above. However, the impact of GO and GO-H202 on the crystalline morphology of the samples was still unknown. To understand fully, polarized optical microscopy obervation during isothermal crystallization process was performed. The samples were heated at $200^{\circ} \mathrm{C}$ for $5 \mathrm{~min}$ and then rapidly cooled to $130^{\circ} \mathrm{C}$ for isothermal crystallization.

Figure 10 shows the morphological evolution of the samples during the isothermal crystallization at $130^{\circ} \mathrm{C}$. It can be seen that at $5 \mathrm{~min}$ after crystallization began, for neat PP, some sporadic nuclei are visible, while for GPP and GHPP, much more amounts of nuclei can be seen, indicating that after the addition of GO or GO-H202, the nucleation rate of the composites is evidently enhanced, which is in accordance with the DSC analysis above; as the crystallization time increases, at $10 \mathrm{~min}$, it can be observed that the spherulites grow continuously; at $15 \mathrm{~min}$, GHPP finished crystallization, and the crystallites occupied the whole image, while for neat PP and GPP, the crystallization was not finished yet.

(a) PP
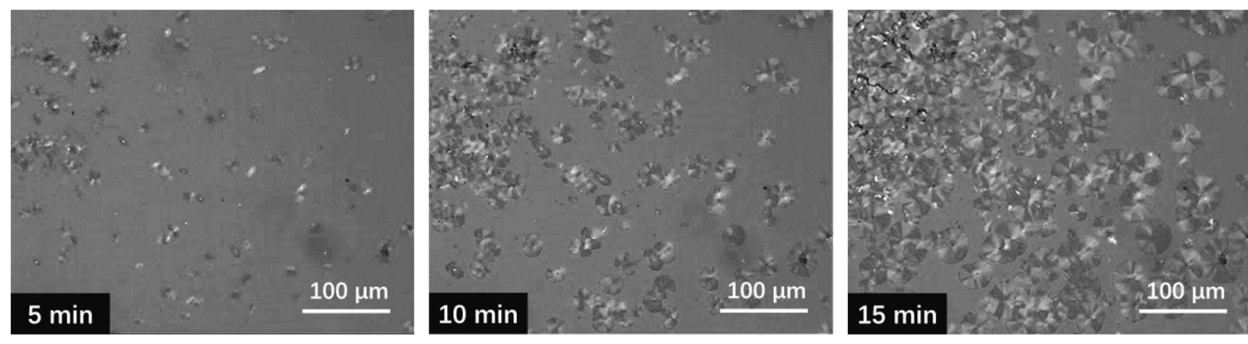

Figure 10. Cont. 


\section{(b) GPP}
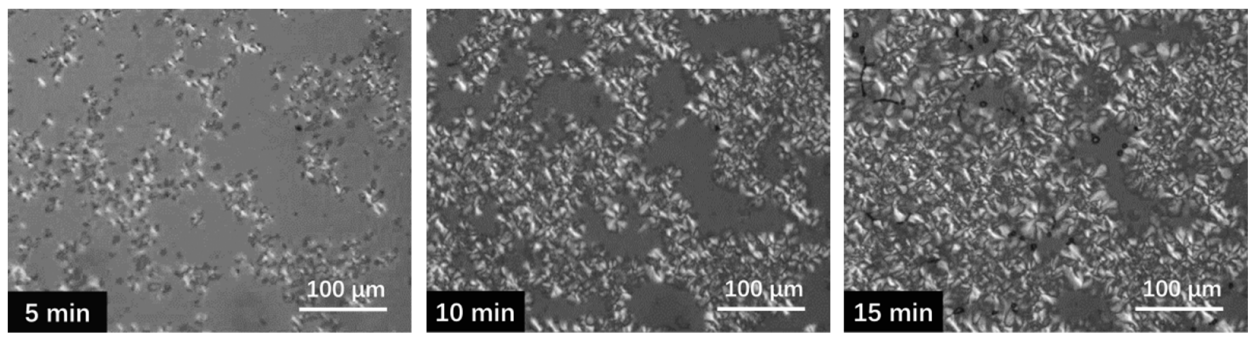

(c) GHPP
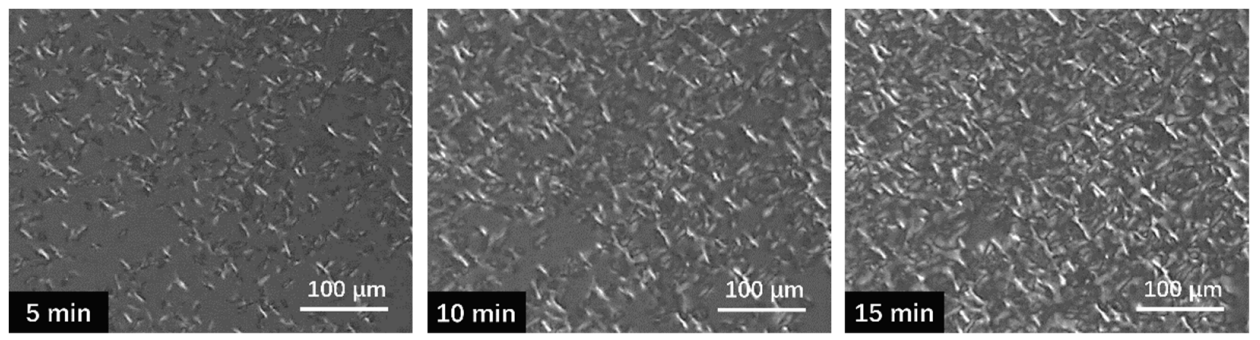

Figure 10. Polarized optical microscopy (POM) images during the isothermal crystallization at $130{ }^{\circ} \mathrm{C}$ of (a) neat PP, (b) GPP, and (c) GHPP.

Interestingly, the shape of the crystallites of GHPP is quite different from GPP and neat PP. Considering that the Avrami exponent $n$ changed after the addition of GO-H202 (Figure $6 \mathrm{~d}$ ), it is proposed that the addition of GO-H202 might change the nucleation and crystal growth manner and further change the crystallite morphology of the composites.

\section{Conclusions}

In this study, we prepared the hyperbranched polyester grafted GO (GO-H202) and the iPP/GO composites. Results of XPS, FT-IR, and TEM revealed the successful grafting of $\mathrm{H} 202$ onto GO, and TGA indicated that the weight ratio of grafting was about $35 \mathrm{wt} \%$. DSC analysis and POM observation were carried out to investigate the role of GO and GO-H202 on the crystallization kinetics of the composites. Results of conventional cooling and heating scan suggested that the addition of GO enhances the nucleation rate and crystallizability of the composites, while GO-H202 exhibits a higher crystallization acceleration effect compared with GO. Results of isothermal crystallization kinetics and self-nucleation isothermal crystallization kinetics showed that the overall crystallization rate (involving both nucleation and crystal growth) and crystal growth rate increase after the addition of GO and GO-H202. The crystallization acceleration of GO-H202 became stronger compared with GO. Moreover, the variation trends of Avrami exponent $n$ with the isothermal crystallization temperature $T_{\text {cISO }}$ changed significantly from PP, GPP to GHPP, which might imply that the addition of GO and GO-H202 led to different crystallization dimensionalities during the isothermal crystallization of the composites.

Author Contributions: Conceptualization, Z.H.; methodology, L.L.; validation, L.L. and B.Y.; formal analysis, X.S. and X.L.; resources, L.H.; writing—original draft preparation, Z.H.; writing—review and editing, L.L. and B.Y.; visualization, P.L.; project administration, L.L. and B.Y.

Funding: This research was funded by National Natural Science Foundation of China, grant number 51702282, the Key industry technology innovation projects of Chongqing, grant number CSTC2017zdcy-zdyf0297 and the leading Talents of Scientific and Technological Innovation of Chongqing, grant number cstccxljrc201720.

Acknowledgments: We gratefully acknowledge the financial support from the National Natural Science Foundation of China (51702282), the Key industry technology innovation projects of Chongqing (CSTC2017zdcy-zdyf0297), and the leading Talents of Scientific and Technological Innovation of Chongqing (cstccxljrc201720).

Conflicts of Interest: The authors declare no conflict of interest. 


\section{References}

1. Natta, G.; Corradini, P. Structure and properties of isotactic polypropylene. Nuovo Cim. 1960, 15, 40-51. [CrossRef]

2. Natta, G.; Pino, P.; Corradini, P.; Danusso, F.; Mantica, E.; Mazzanti, G.; Moraglio, G. Crystalline high polymers of $\alpha$-olefins. J. Am. Chem. Soc. 1955, 77, 1708-1710. [CrossRef]

3. Zeng, F.; Chen, J.; Yang, F.; Kang, J.; Cao, Y.; Xiang, M. Effects of Polypropylene Orientation on Mechanical and Heat Seal Properties of Polymer-Aluminum-Polymer Composite Films for Pouch Lithium-Ion Batteries. Materials 2018, 11, 144. [CrossRef] [PubMed]

4. Xiong, B.; Chen, R.; Zeng, F.; Kang, J.; Men, Y. Thermal shrinkage and microscopic shutdown mechanism of polypropylene separator for lithium-ion battery: In-situ ultra-small angle X-ray scattering study. J. Membr. Sci. 2018, 545, 213-220. [CrossRef]

5. Yu, Y.; Xiong, B.; Zeng, F.; Xu, R.; Yang, F.; Kang, J.; Xiang, M.; Li, L.; Sheng, X.; Hao, Z. Influences of Compression on the Mechanical Behavior and Electrochemical Performances of Separators for Lithium Ion Batteries. Ind. Eng. Chem. Res. 2018, 57, 17142-17151. [CrossRef]

6. Liu, Z.; Liu, X.; Zheng, G.; Dai, K.; Liu, C.; Shen, C.; Yin, R.; Guo, Z. Mechanical enhancement of melt-stretched $\beta$-nucleated isotactic polypropylene: The role of lamellar branching of $\beta$-crystal. Polym. Test. 2017, 58, 227-235. [CrossRef]

7. Xiong, J.K.B.; Chen, R.; Men, Y. Initiation of cavitation upon drawing of pre-oriented polypropylene film: In situ SAXS and WAXD studies. Polymer 2017, 128, 57-64. [CrossRef]

8. Zhang, C.; Wang, B.; Yang, J.; Ding, D.; Yan, X.; Zheng, G.; Dai, K.; Liu, C.; Guo, Z. Synergies among the self-assembled $\beta$-nucleating agent and the sheared isotactic polypropylene matrix. Polymer 2015, 60, 40-49. [CrossRef]

9. Kang, J.H.J.; Chen, Z.; Yu, H.; Chen, J.; Yang, F.; Cao, Y.; Xiang, M. Investigation on the crystallization behavior and polymorphic composition of isotactic polypropylene / multi-walled carbon nanotubes composites nucleated with $\beta$-nucleating agent-The role of melt structures. J. Therm. Anal. Calorim. 2015, 119, 1769-1780. [CrossRef]

10. Bruckner, S.; Meille, S.V.; Petraccone, V.; Pirozzi, B. Polymorphism in isotactic polypropylene. Prog. Polym. Sci. 1991, 16, 361-404. [CrossRef]

11. Kang, J.; Chen, J.; Cao, Y.; Li, H. Effects of ultrasound on the conformation and crystallization behavior of isotactic polypropylene and [beta]-isotactic polypropylene. Polymer 2010, 51, 249-256. [CrossRef]

12. Kang, J.; Weng, G.; Chen, Z.; Chen, J.; Cao, Y.; Yang, F.; Xiang, M. New understanding in the influence of melt structure and $\beta$-nucleating agents on the polymorphic behavior of isotactic polypropylene. Rsc Adv. 2014, 56, 29514-29526. [CrossRef]

13. Yansong, Y.; Fangxinyu, Z.; Jinyao, C.; Jian, K.; Feng, Y.; Ya, C.; Ming, X. Isothermal Crystallization Kinetics and Subsequent Melting Behavior of $\beta$-Nucleated Isotactic Polypropylene / Graphene Oxide Composites with Different Ordered Structure. Polym. Int. 2018. [CrossRef]

14. Brückner, S.; Phillips, P.J.; Mezghani, K.; Meille, S.V. On the crystallization of $\gamma$-isotactic polypropylene: A high pressure study. Macromol. Rapid Commun. 1997, 18, 1-7. [CrossRef]

15. Krache, R.; Benavente, R.; López-Majada, J.M.; Pereña, J.M.; Cerrada, M.L.; Pérez, E. Competition between $\alpha, \beta$, and $\gamma$ Polymorphs in a $\beta$-Nucleated Metallocenic Isotactic Polypropylene. Macromolecules 2007, 40, 6871-6878. [CrossRef]

16. Horvath, Z.; Sajó, I.E.; Stoll, K.; Menyhárd, A.; Varga, J. The effect of molecular mass on the polymorphism and crystalline structure of isotactic polypropylene. Express Polym. Lett. 2010, 4, 101-114. [CrossRef]

17. Varga, J. $\beta$-Modification of Isotactic Polypropylene: Preparation, Structure, Processing, Properties, and Application. J. Macromol. Sci. Part B 2002, 41, 1121-1171. [CrossRef]

18. Zhang, B.; Chen, J.; Ji, F.; Zhang, X.; Zheng, G.; Shen, C. Effects of melt structure on shear-induced $\beta$-cylindrites of isotactic polypropylene. Polymer 2012, 53, 1791-1800. [CrossRef]

19. Kang, J.; He, J.; Chen, Z.; Yang, F.; Chen, J.; Cao, Y.; Xiang, M. Effects of $\beta$-nucleating agent and crystallization conditions on the crystallization behavior and polymorphic composition of isotactic polypropylene/multi-walled carbon nanotubes composites. Polym. Adv. Technol. 2015, 26, 32-40. [CrossRef]

20. Pawlak, A.; Piorkowska, E. Crystallization of isotactic polypropylene in a temperature gradient. Colloid Polym. Sci. 2001, 279, 939-946. [CrossRef] 
21. Qiyan, Z.; Hongmei, P.; Jian, K.; Ya, C.; Ming, X. Effects of melt structure on non-isothermal crystallization behavior of isotactic polypropylene nucleated with $\alpha / \beta$ compounded nucleating agents. Polym. Eng. Sci. 2017, 57, 989-997.

22. Kang, Z.C.J.; Yang, F.; Chen, J.; Cao, Y.; Weng, G.; Xiang, M. Understanding the effects of nucleating agent concentration on the polymorphic behavior of $\beta$-nucleated isotactic polypropylene with different melt structures. Colloid Polym. Sci. 2015, 293, 2061-2073. [CrossRef]

23. Davies, A.; Yu, A. Material advancements in supercapacitors: From activated carbon to carbon nanotube and graphene. Can. J. Chem. Eng. 2011, 89, 1342-1357. [CrossRef]

24. Dong, X.; Wang, X.; Wang, J.; Song, H.; Li, X.; Wang, L.; Chan-Park, M.B.; Li, C.M.; Chen, P. Synthesis of a $\mathrm{MnO}_{2}$-graphene foam hybrid with controlled $\mathrm{MnO}_{2}$ particle shape and its use as a supercapacitor electrode. Carbon 2012, 50, 4865-4870. [CrossRef]

25. Choi, H.-J.; Jung, S.-M.; Seo, J.-M.; Chang, D.W.; Dai, L.; Baek, J.-B. Graphene for energy conversion and storage in fuel cells and supercapacitors. Nano Energy 2012, 1, 534-551. [CrossRef]

26. Yang, X.; Zhu, J.; Qiu, L.; Li, D. Bioinspired effective prevention of restacking in multilayered graphene films: Towards the next generation of high-performance supercapacitors. Adv. Mater. 2011, 23, $2833-2838$. [CrossRef] [PubMed]

27. Jaidev, S. Ramaprabhu, Poly(p-phenylenediamine)/graphene nanocomposites for supercapacitor applications. J. Mater. Chem. 2012, 22, 18775. [CrossRef]

28. Chae, H.-R.; Lee, J.; Lee, C.-H.; Kim, I.-C.; Park, P.-K. Graphene oxide-embedded thin-film composite reverse osmosis membrane with high flux, anti-biofouling, and chlorine resistance. J. Membr. Sci. 2015, 483, 128-135. [CrossRef]

29. Bao, R.-Y.; Cao, J.; Liu, Z.-Y.; Yang, W.; Xie, B.-H.; Yang, M.-B. Towards balanced strength and toughness improvement of isotactic polypropylene nanocomposites by surface functionalized graphene oxide. J. Mater. Chem. A 2014, 2, 3190-3199. [CrossRef]

30. Yu, Y.; Zeng, F.; Chen, J.; Kang, J.; Yang, F.; Cao, Y.; Xiang, M. Regulating polycrystalline behavior of the $\beta$-nucleated isotactic polypropylene/graphene oxide composites by melt memory effect. Polym. Compos. 2018. [CrossRef]

31. Hao, Z.; Li, L.; Liao, X.; Sheng, X.; Zhang, Y. Preparation and toughening performance investigation of epoxy resins containing carbon nanotubes modified with hyperbranched polyester. Polym. Bull. 2018, 75, 1013-1026. [CrossRef]

32. Zhang, J.; Hu, C.P. Synthesis, characterization and mechanical properties of polyester-based aliphatic polyurethane elastomers containing hyperbranched polyester segments. Eur. Polym. J. 2008, 44, 3708-3714. [CrossRef]

33. Han, W.; Liao, X.; Yang, Q.; Li, G.; He, B.; Zhu, W.; Hao, Z. Crystallization and morphological transition of poly(l-lactide)-poly(E-caprolactone) diblock copolymers with different block length ratios. Rsc Adv. 2017, 7, 22515-22523. [CrossRef]

34. Hao, Z.; Tan, Y.; Zhang, X.; Zhang, F. Epithermal ageing mechanism of gussasphalt. J. Wuhan Univ. Technol. Mater. Sci. Ed. 2009, 24, 466-470. [CrossRef]

35. Lu, L.; Xia, L.; Zengheng, H.; Xingyue, S.; Yi, Z.; Pan, L. Investigation on cure kinetics of epoxy resin containing carbon nanotubes modified with hyper-branched polyester. Rsc Adv. 2018, 8, 29830-29839. [CrossRef]

36. Yu, Y.; Zeng, F.; Chen, J.; Kang, J.; Yang, F.; Cao, Y.; Xiang, M. Effects of ordered structure on non-isothermal crystallization kinetics and subsequent melting behavior of $\beta$-nucleated isotactic polypropylene/graphene oxide composites. J. Therm. Anal. Calorim. 2018, 67, 1212-1220. [CrossRef]

37. Xu, R.; Xu, G.; Wang, J.; Chen, J.; Yang, F.; Kang, J.; Xiang, M. Influence of l-lysine on the permeation and antifouling performance of polyamide thin film composite reverse osmosis membranes. Rsc Adv. 2018, 8, 25236-25247. [CrossRef]

38. Xu, R.; Wang, J.; Chen, D.; Yang, F.; Kang, J.; Xiang, M.; Li, L.; Sheng, X. Preparation of pH-responsive asymmetric polysulfone ultrafiltration membranes with enhanced anti-fouling properties and performance by incorporating poly(2-ethyl-2-oxazoline) additive. Rsc Adv. 2018, 8, 41270-41279. [CrossRef]

39. Wang, J.; Xu, R.; Yang, F.; Kang, J.; Cao, Y.; Xiang, M. Probing influences of support layer on the morphology of polyamide selective layer of thin film composite membrane. J. Membr. Sci. 2018, 556, 374-383. [CrossRef] 
40. Qin, Y.; Xu, Y.; Zhang, L.; Zheng, G.; Yan, X.; Dai, K.; Liu, C.; Shen, C.; Guo, Z. Interfacial interaction enhancement by shear-induced $\beta$-cylindrite in isotactic polypropylene/glass fiber composites. Polymer 2016, 100, 111-118. [CrossRef]

41. Kang, J.; Yang, F.; Wu, T.; Li, H.; Cao, Y.; Xiang, M. Polymerization control and fast characterization of the stereo-defect distribution of heterogeneous Ziegler-Natta isotactic polypropylene. Eur. Polym. J. 2012, 48, 425-434. [CrossRef]

42. Zhang, L.; Qin, Y.; Zheng, G.; Dai, K.; Liu, C.; Yan, X.; Guo, J.; Shen, C.; Guo, Z. Interfacial crystallization and mechanical property of isotactic polypropylene based single-polymer composites. Polymer 2016, 90, 18-25. [CrossRef]

43. Sun, S.; Zhu, L.; Liu, X.; Wu, L.; Dai, K.; Liu, C.; Shen, C.; Guo, X.; Zheng, G.; Guo, Z. Superhydrophobic Shish-kebab Membrane with Self-Cleaning and Oil/Water Separation Properties. Acs Sustain. Chem. Eng. 2018, 6, 9866-9875. [CrossRef]

44. Kang, J.; Chen, Z.; Chen, J.; Yang, F.; Weng, G.; Cao, Y.; Xiang, M. Crystallization and melting behaviors of the $B$-nucleated isotactic polypropylene with different melt structures-The role of molecular weight. Thermochim. Acta 2015, 599, 42-51. [CrossRef]

45. Kang, J.Z.J.; Chen, Z.; Yang, F.; Chen, J.; Cao, Y.; Xiang, M. Isothermal crystallization behavior of $\beta$-nucleated isotactic polypropylene with different melt structures. J. Polym. Res. 2014. [CrossRef]

46. Kang, J.; Cao, Y.; Li, H.; Li, J.; Chen, S.; Yang, F.; Xiang, M. Influence of the stereo-defect distribution on the crystallization behavior of Ziegler-Natta isotactic polypropylene. J. Polym. Res. 2012, 19, 1-11. [CrossRef]

47. Kang, J.; Li, J.; Chen, S.; Zhu, S.; Li, H.; Cao, Y.; Yang, F.; Xiang, M. Hydrogenated petroleum resin effect on the crystallization of isotactic polypropylene. J. Appl. Polym. Sci. 2013, 130, 25-38. [CrossRef]

48. Lorenzo, A.T.; Müller, A.J. Estimation of the nucleation and crystal growth contributions to the overall crystallization energy barrier. J. Polym. Sci. Part B Polym. Phys. 2008, 46, 1478-1487. [CrossRef]

49. Müller, A.J.; Arnal, M.L. Thermal fractionation of polymers. Prog. Polym. Sci. 2005, 30, 559-603. [CrossRef]

50. Fillon, B.; Wittmann, J.; Lotz, B.; Thierry, A. Self-nucleation and recrystallization of isotactic polypropylene ( $\alpha$ phase) investigated by differential scanning calorimetry. J. Polym. Sci. Part B Polym. Phys. 1993, 31, 1383-1393. [CrossRef]

51. Fillon, B.; Thierry, A.; Wittmann, J.; Lotz, B. Self-nucleation and recrystallization of polymers. Isotactic polypropylene, $\beta$ phase: $\beta-\alpha$ conversion and $\beta$ - $\alpha$ growth transitions. J. Polym. Sci. Part B Polym. Phys. 1993, 31, 1407-1424. [CrossRef]

52. Fillon, B.; Lotz, B.; Thierry, A.; Wittmann, J. Self-nucleation and enhanced nucleation of polymers. Definition of a convenient calorimetric "efficiency scale" and evaluation of nucleating additives in isotactic polypropylene ( $\alpha$ phase). J. Polym. Sci. Part B Polym. Phys. 1993, 31, 1395-1405. [CrossRef]

53. Wang, B.; Chen, Z.; Kang, J.; Yang, F.; Chen, J.; Cao, Y.; Xiang, M. Influence of melt structure on the crystallization behavior and polymorphic composition of polypropylene random copolymer. Thermochim. Acta 2015, 604, 67-76. [CrossRef]

54. Kang, J.; Chen, Z.; Zhou, T.; Yang, F.; Chen, J.; Cao, Y.; Xiang, M. Dynamic crystallization and melting behavior of $\beta$-nucleated isotactic polypropylene with different melt structures. J. Polym. Res. 2014. [CrossRef]

55. Chen, Z.; Wang, B.; Kang, J.; Peng, H.; Chen, J.; Yang, F.; Cao, Y.; Li, H.; Xiang, M. Crystallization behavior and morphology of $\beta$-nucleated isotactic polypropylene with different stereo-defect distribution. Polym. Adv. Technol. 2014, 25, 353-363. [CrossRef]

56. Kang, J.; Li, J.; Chen, S.; Peng, H.; Wang, B.; Cao, Y.; Li, H.; Chen, J.; Gai, J.; Yang, F.; et al. Investigation of the crystallization behavior of isotactic polypropylene polymerized with different Ziegler-Natta catalysts. J. Appl. Polym. Sci. 2013, 129, 2663-2670. [CrossRef]

57. Kang, G.W.J.; Chen, J.; Yang, F.; Cao, Y.; Xiang, M. Influences of pre-ordered melt structures on the crystallization behavior and polymorphic composition of $\beta$-nucleated isotactic polypropylene with different stereo-defect distribution. J. Appl. Polym. Sci. 2015, 132, 42632. [CrossRef]

58. Peng, H.; Wang, B.; Gai, J.; Chen, J.; Yang, F.; Cao, Y.; Li, H.; Kang, J.; Xiang, M. Morphology and mechanical behavior of isotactic polypropylene with different stereo-defect distribution in injection molding. Polym. Adv. Technol. 2014, 25, 1464-1470. [CrossRef]

59. Müller, A.J.; Michell, R.M.; Pérez, R.A.; Lorenzo, A.T. Successive Self-nucleation and Annealing (SSA): Correct design of thermal protocol and applications. Eur. Polym. J. 2015, 65, 132-154. [CrossRef] 
60. Hoffman, J.D.; Miller, R.L. Kinetic of crystallization from the melt and chain folding in polyethylene fractions revisited: Theory and experiment. Polymer 1997, 38, 3151-3212. [CrossRef]

61. Clark, E.J.; Hoffman, J.D. Regime III crystallization in polypropylene. Macromolecules 1984, 17, $878-885$. [CrossRef]

62. Hoffman, J.D.; Miller, R.L. Response to criticism of nucleation theory as applied to crystallization of lamellar polymers. Macromolecules 1989, 22, 3502-3505. [CrossRef]

63. Hoffman, J.D.; Miller, R.L. Test of the reptation concept: Crystal growth rate as a function of molecular weight in polyethylene crystallized from the melt. Macromolecules 1988, 21, 3038-3051. [CrossRef]

C 2019 by the authors. Licensee MDPI, Basel, Switzerland. This article is an open access article distributed under the terms and conditions of the Creative Commons Attribution (CC BY) license (http:/ / creativecommons.org/licenses/by/4.0/). 